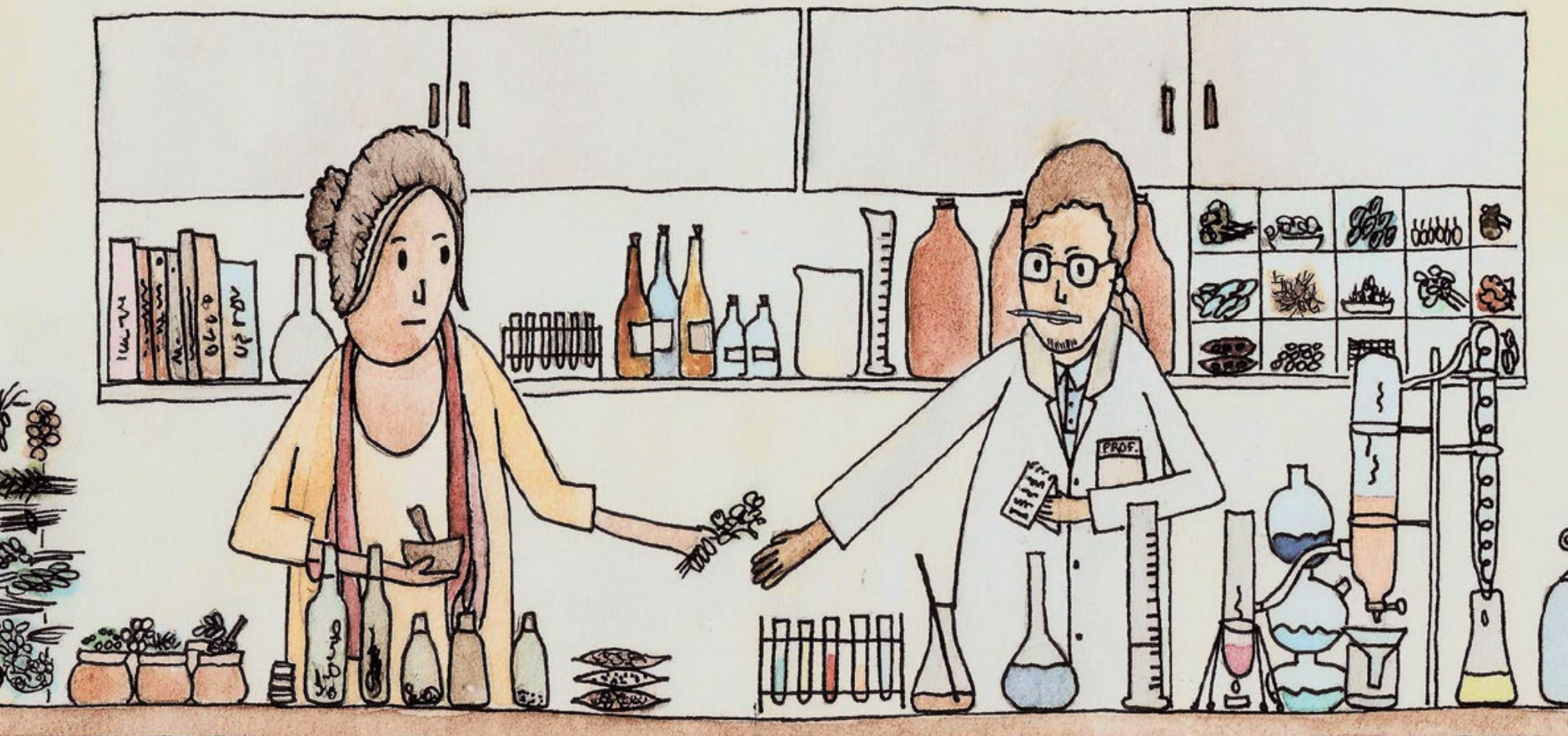

\title{
A UNIVERSIDADE E 0 SABER POPULAR
}

Leonardo Boff'

O povo brasileiro ainda não acabou de nascer. Vindos de 60 países diferentes, aqui estão se mesclando representantes destes povos num processo aberto, todos contribuindo na gestação de um povo novo que um dia acabará de nascer.

O que herdamos da Colônia foi um Estado altamente seletivo, uma elite excludente e uma imensa massa de destituídos e descendentes de escravos. O cientista político Luiz Gonzaga de Souza Lima na sua original interpretação do Brasil nos diz que nascemos como Empresa transnacionalizada, condenada a ser até hoje fornecedora de produtos in natura para o mercado mundial (LIMA, 2011).
Mas apesar deste constrangimento histórico-social, no meio desta massa enorme maduraram lentamente lideranças e movimentos que propiciaram o surgimento de todo tipo de comunidades, associações, grupos de ação e de reflexão que vão das quebradeiras de coco do Maranhão, aos povos da floresta do Acre, dos sem-terra do sul e do norte, das comunidades de base, aos sindicatos do ABC paulista.

Do exercício democrático no interior destes movimentos nasceram cidadãos ativos; da articulação entre eles, cada um mantendo sua autonomia, está nascendo uma energia geradora do povo brasileiro que lentamente 
chega à consciência de sua história e projeta um futuro diferente e melhor para todos.

Nenhum processo desta magnitude se faz sem aliados, sem a ligação orgânica daqueles que manejam um saber especializado com os movimentos sociais comprometidos. É aqui que a universidade é desafiada a alargar o seu horizonte. Importa que os mestres e alunos frequentem a escola viva do povo, como praticava Paulo Freire, e permitir que gente do povo possa entrar nas salas de aula e escutar os professores nas matérias relevantes para eles como eu mesmo fazia nos meus cursos na UERJ do Rio de Janeiro nos anos que lá lecionei.

Essa visão supõe a criação de uma aliança entre a inteligência acadêmica com a sabedoria popular. Todas as universidades, especialmente após a reforma de seu estatuto por Humboldt em 1809 em Berlim que permitiu as ciências modernas ganharem sua cidadania acadêmica ao lado da reflexão humanística que criou na Idade Média a universidade, se tornaram o lugar clássico da problematização da cultura, da vida, do homem, de seu destino e de Deus.

As duas culturas - a humanística e a científica - mais e mais se intercomunicam no sentido de pensar o todo, o destino do próprio projeto científico-técnico face às intervenções agressivas que faz na natureza e sua responsabilidade pelo futuro comum da nação e da Terra. Tal desafio exige um novo modo de pensar que não segue uma lógica do simples e linear, mas do complexo e do dialógico.

As universidades são urgidas a buscar um enraizamento orgânico com as periferias, com as bases populares e com os setores ligados diretamente à produção. Aqui pode se estabelecer uma fecunda troca de saberes, entre o saber popular, de experiências feito, e o saber acadêmico, constituído pelo espírito crítico. Dessa aliança surgirão seguramente novas temáticas teóricas nascidas do confronto com a anti-realidade popular e da valorização da riqueza incomensurável do povo na sua capacidade de encontrar, sozinho, saídas para os seus problemas. Aqui se dá a troca de saberes, uns completando os outros, no estilo proposto pelo prêmio Nobel de Química (1977) Ilya Prigogine: a convivência e aliança entre todos os saberes, desde os mais comezinhos como de uma benzedeira, de um conhecedor popular de ervas medicinais e um mestre em física ou em psicologia. Cada saber representa uma janela aberta sobre a realidade que, no fundo, não sabemos o que é, mas que pelas muitas achegas mais e mais a podemos decifrar. (PRIGOGINE, 1984).

Deste casamento, se acelera a gênese de um povo; permite um novo tipo de cidadania, baseada na con-cidadania dos representantes da sociedade civil e acadêmica e das bases populares que tomam iniciativas por si mesmos e submetem o Estado a um controle democrático, cobrando-lhe os serviços básicos de saúde, educação, segurança, transporte, cultura e lazer, especialmente para as grandes populações periféricas.

Nestas iniciativas populares, com suas várias frentes (casa, saúde, educação, direitos humanos, transporte coletivo etc), os movimentos sociais sentem necessidade de um saber profissional. É onde a universidade pode e deve entrar, socializando o saber, oferecendo encaminhamentos para soluções originais e abrindo perspectivas às vezes insuspeitadas por quem é condenado a lutar só para sobreviver. Deste ir-e-vir fecundo entre pensamento universitário e saber popular pode surgir o biorregionalismo com um desenvolvimento adequado àquele ecossistema e à cultura local. A partir desta prática, a universidade pública resgatará seu caráter público, será realmente a servidora da sociedade. E a universidade privada realizará sua função social, já que em grande parte é refém dos interesses privados das classes proprietárias e feita chocadeira de sua reprodução social. 
Esse processo dinâmico e contraditório só prosperará se estiver imbuído de um grande sonho: de ser um povo novo, autônomo livre e orgulhoso de sua terra. O antropólogo Roberto DaMatta bem enfatizou que o povo brasileiro criou um patrimônio realmente invejável: "toda essa nossa capacidade de sintetizar, relacionar, reconciliar, criando com isso zonas e valores ligados à alegria, ao futuro e à esperança" (DAMATTA, 1986, p. 121).

Apesar de todas tribulações históricas, apesar de ter sido considerado, tantas vezes, jeca-tatu e joão-ninguém, o povo brasileiro nunca perdeu sua auto- estima e o encantamento do mundo. É um povo de grandes sonhos, de esperanças inarredáveis e utopias generosas, um povo que se sente tão imbuído pelas energias divinas que estima ser Deus brasileiro.

Talvez seja esta visão encantada do mundo, uma das maiores contribuições que nós brasileiros podemos dar à cultura mundial emergente, tão pouco mágica e tão pouco sensível ao jogo, ao humor e à convivência dos contrários.

\section{REFERÊNCIAS}

DAMATTA, Roberto. O que faz o Brasil, Brasil. Rio de Janeiro: Rocco, 1986.

LIMA, Luiz G. S. A refundação do Brasil: rumo a uma civilização biocentrada, São Carlos/ SP: Rima, 2011.

PRIGOGINE, Ilya. A nova aliança. Brasília: Editora UnB, 1984. 


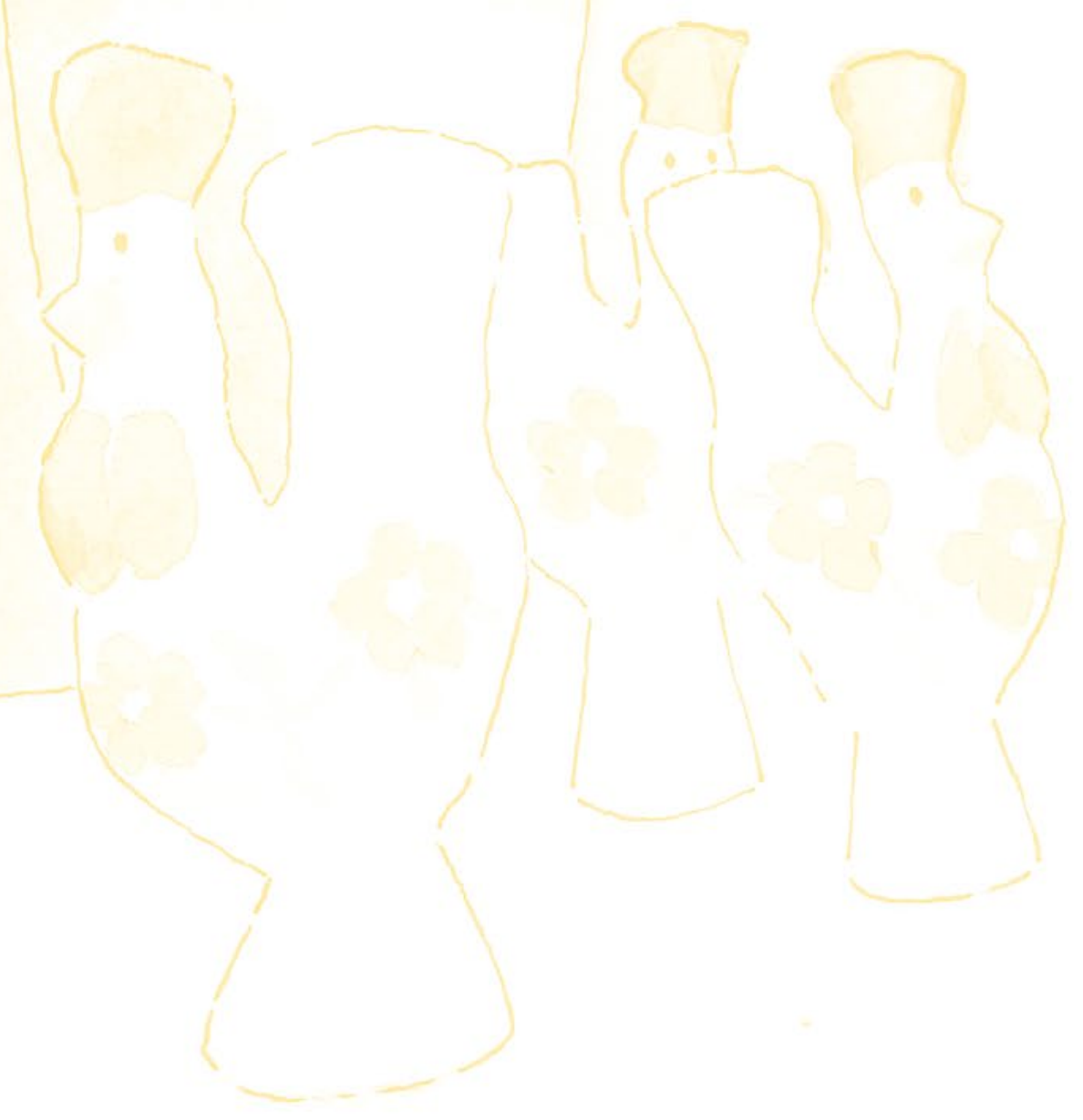

